\title{
Evaluation of Patients' Knowledge Regarding Smoking and Chronic Pancreatitis: A Pilot Study
}

\author{
Josna Haritha* and C. Mel Wilcox \\ Division of Gastroenterology and Hepatology, University of Alabama at Birmingham, Birmingham, Alabama, USA
}

Received: May 05, 2014; Accepted: July 02, 2014; Published: July 15, 2014

*Corresponding author: C. Mel Wilcox, M.D., M.S.P.H., Basil I. Hirschowitz Endoscopic Center of Excellence, Division of Gastroenterology and Hepatology, 1720 2nd Ave., South, BDB 380, Birmingham, Alabama 35294-0113, Tel: 205-975-4958; Fax: 205-934-8493, E-mail: melw@uab.edu

\begin{abstract}
Objective: Over the last decade, a strong association has been found between smoking and chronic pancreatitis. Some studies suggest that smoking may be a more important cause of chronic pancreatitis than alcohol and the two are additive. The primary purpose of our study was to test the use of a questionnaire to assess patient's knowledge regarding the association of smoking with pancreatic disease.

Methods: The questionnaire was administered prospectively during a 9 month period in 2013 to patients referred to a pancreas clinic at the University of Alabama Birmingham. The primary purpose of the questionnaire was to investigate patient awareness regarding the association of smoking with pancreatic disease; however, it was also designed for assessing doctor-patient communication regarding smoking in general and pancreatic disease specifically and the patient's stage of change for quitting smoking.

Results: Eighteen patients (mean age 52 years; 85\% male) were used for the analysis. The data analysis showed that $56 \%$ of patients were aware of the relationship between smoking and chronic pancreatitis and $72 \%$ were aware about alcohol and pancreatitis. Patients related that physicians were an important reference source for their knowledge regarding the causes of chronic pancreatitis, but only $39 \%$ stated that their physician had specifically mention the effect of smoking on the pancreas.

Conclusion: Elaborate studies involving greater number of study population, are necessary to better define measuring tools and to further assess patient's knowledge regarding the relationship between smoking and chronic pancreatitis. Additionally, efforts should be directed towards enhancing physician's knowledge on this established relationship and the importance of patient education as well.
\end{abstract}

Keywords: Smoking; Acute pancreatitis; Chronic pancreatitis Pancreatic cancer

\section{Introduction}

Chronic pancreatitis is a long-standing inflammatory disease of the pancreas that is characterized by abdominal pain and which may be complicated by maldigestion, diabetes mellitus and even pancreatic cancer [1]. Unlike acute pancreatitis, a reversible condition, chronic pancreatitis is defined by a chronic, irreversible inflammation that leads to fibrosis and calcifications. While there are many causes of chronic pancreatitis, 90-95\% of patients presenting with this condition are classified as alcoholic or idiopathic in etiology [1].
Recently, smoking has been identified as a major independent risk factor for chronic pancreatitis [2-7]. Along with alcohol, smoking is a strong lifestyle factor used to predict a patient's risk of developing pancreatitis [1]. Smoking has an additive effect when combined with alcohol [4] making it imperative that physicians stress both smoking and alcohol cessation. Law et al. [5] found that smoking and its association with chronic pancreatitis can be considered independent of alcohol, is dosedependent and increases with alcohol consumption.

Yadav and colleagues [7] as part of a North American Pancreatitis Study evaluated the frequency by which smoking was considered a risk factor by treating physicians for chronic pancreatitis. In this extensive study, of the $71 \%$ of chronic pancreatitis patients who reported that they had ever smoked, their physicians cited smoking as a risk factor in only $45 \%$ (173/382). Physicians were more likely to attribute smoking to chronic pancreatitis when patients were actively smoking and with higher amount and duration. Nevertheless, there was a wide variability in the reporting of smoking as a risk factor. This study was important because it went beyond linking smoking to the progression of chronic pancreatitis and examined whether physicians recognized smoking as a risk factor. The results of this study showed that although scientific evidence and physicians themselves know that smoking influences the progression of this disease, only $45.3 \%$ of physicians reported tobacco use as a risk factor in those patients who had smoked [3].

With the overwhelming evidence that smoking is an independent risk factor for chronic pancreatitis and accelerates its progression, it is prudent to apply this knowledge to patient care and stress primary and secondary prevention. Importantly, a study from 2007 showed that patients who quit smoking within one year of being diagnosed with chronic pancreatitis significantly reduced their risk of developing calcifications [8].

Given the association of smoking with chronic pancreatitis coupled with evidence that many physicians fail to link smoking as a risk factor [7], we hypothesized that many patients with chronic pancreatitis are unaware of this association. The primary aim of this study was to assess, in patients with chronic pancreatitis, their knowledge regarding the association of 
smoking and pancreatic disease. Secondary measures to study were the importance of their physicians in education as well as their personal desire to quit smoking.

\section{Instrumentation}

A 25-item questionnaire was developed by one of the investigators $(\mathrm{JH})$ to investigate patient awareness regarding the association of smoking with pancreatic disease; however, it was also designed for assessing doctor-patient communication regarding smoking in general and pancreatic disease specifically and the patient's stage of change for quitting smoking. The questionnaire was divided into three sections. The first section (Items 1-12) focused on gathering information about the patient's smoking history. These items divided the participants into current and former smokers. The second section (Items 1316) evaluated whether the physician incorporated the discussion of smoking and its health risks into regular appointments. The third and last section (Items 17-25) assessed the patient's level of education about smoking and how it increases the risk of developing pancreatitis. The final few items were used to determine the stage of change or willingness of the patient to quit smoking, either now or later. The study was approved by the Institutional Review Board and all patients gave written informed consent.

\section{Sampling}

The questionnaire was administered to patients that met two criteria: First, they had a smoking history or were a current smoker, and second, they had imaging evidence of chronic pancreatitis. The questionnaire was given to patients during a visit to our Pancreas Clinic during a 9 month study period in 2013. All patients were evaluated by an investigator (CMW). All personal information was kept anonymous. During the period of study, approximately 60 patients with bonafide chronic pancreatitis were evaluated.

\section{Results}

A total of 20 questionnaires were collected. Two patients were excluded after re-review of abdominal computed tomography radiographs failed to confirm chronic pancreatitis. Thus, 18 questionnaires were analyzed. During the period of study we evaluated approximately 60 patients. The mean age of the patients was 52 years (range $41-70$ years); $85 \%$ were male, and $80 \%$ were Caucasian. The cause of chronic pancreatitis was determined based on history and imaging studies. The most common cause was alcohol and smoking in 13 patients (65\%), smoking alone in $20 \%$ and one patient each with familial pancreatitis, post necrotic chronic pancreatitis (following acute necrotic episode), and late stage autoimmune pancreatitis. The diagnosis of chronic pancreatitis was made by abdominal CT in all but 4 patients who had 5 or greater criteria for chronic pancreatitis on endoscopic ultrasonography.

The first twelve questions of the survey examined the smoking history of the patients (Table 1). Of the 13 current smokers, 11 smoked cigarettes with a 0.89 pack/day average and the other two subjects smoked cigars with an average of 4.5 cigars/day. Among the smokers $(n=13)$, the average length of smoking in years was 26.7 years. Six of the 13 current smokers had attempted to quit in the past with an average quit time of 3.8 months and an average number of attempts of 2.7. Among those six patients that attempted to quit smoking, the top reason was personal choice. The method of smoking cessation was split with three going "cold turkey" and three using medication (Chantix, Wellbutrin, etc). The number one cause of relapse was the unbearable urge or desire to start smoking again.

The second half of the questionnaire assessed the patient's level of education about smoking and chronic pancreatitis as well as the effectiveness of the communication between physicians and their patients. The next questions examined whether the physician mentioned smoking and its health risks (Table 2). Twelve of 18 (67\%) patients said that their physician mentioned smoking and its health risks at many appointments (5-10 visits). Of the 18 patients, 15 said that the doctor personalized the risks of smoking to their own health with lung cancer $(10 / 18)$ and

Table 1: Smoking history of the study cohort.

\begin{tabular}{|l|c|c|c|c|}
\hline Do you smoke? & Yes $13(72 \%)$ & No $5(28 \%)$ & 1(5) & $2(1)$ \\
\hline $\begin{array}{l}\text { Of the smokers, how much do you smoke per day } \\
\text { (packs), N }\end{array}$ & $<1 / 2(1)$ & Cigars (2) \\
\hline $\begin{array}{l}\text { What do you smoke? (Cigarettes, cigars, } \\
\text { electronic cigarettes, other) }\end{array}$ & Cigarettes $11(61 \%)$ & Cigars 2 (11\%) & & \\
\hline Have you attempted to quit smoking before? & Yes $6(46 \%)$ & & No $7(54 \%)$ & \\
\hline How long did you quit smoking, mean & 3.8 months & & & \\
\hline Why did you try to quit smoking at that time? & Personal Choice $100 \%$ & & & \\
\hline What caused you to relapse? & Unbearable urge (5) & Lack of support (1) & & \\
\hline
\end{tabular}

Table 2: Knowledge regarding the relationship between smoking and chronic pancreatitis.

\begin{tabular}{|l|c|c|}
\hline Before today's visit has your doctor talked to you previously about smoking and its health risks? & Yes $12(67 \%)$ & No $6(33 \%)$ \\
\hline Did your doctor tell you how smoking personally affects your health? & Yes $15(83 \%)$ & No $3(17 \%)$ \\
\hline If discussed what were the primary reasons given by your physician? & $\begin{array}{c}\text { Lung cancer } \\
10(56 \%)\end{array}$ & $\begin{array}{c}\text { Other health problems } \\
12(67 \%)\end{array}$ \\
\hline
\end{tabular}


Table 3: Relationship between patients' knowledge about smoking and pancreatic disease.

\begin{tabular}{|l|c|c|}
\hline Which of the following cause damage to the pancreas? & $\begin{array}{c}\text { Alcohol } \\
13(72 \%)\end{array}$ & $\begin{array}{c}\text { Smoking } \\
10(56 \%)\end{array}$ \\
\hline Does smoking cause damage to the pancreas? & Yes (9) & No (6) \\
\hline \begin{tabular}{l|c|} 
If yes, where did you learn about the relationship between pancreatic disease and \\
smoking?
\end{tabular} & $\begin{array}{c}\text { Physician } \\
10(56 \%)\end{array}$ & Unsure (3) \\
\hline
\end{tabular}

Table 4: Status of patients' desire to quit smoking.

\begin{tabular}{|c|c|c|c|}
\hline When your doctor mentioned smoking as a risk did it make you want to quit? & $\begin{array}{c}\text { Yes } \\
10(56 \%)\end{array}$ & $\begin{array}{c}\text { No } \\
8(44 \%)\end{array}$ & \\
\hline Did your doctor tell you to consider quitting smoking because it would damage your pancreas? & $\begin{array}{c}\text { Yes } \\
11(61 \%)\end{array}$ & $\begin{array}{c}\text { No } \\
7(39 \%)\end{array}$ & \\
\hline If your physician told you that smoking causes pancreatic disease would that motivate you to quit? & $\begin{array}{c}\text { Yes } \\
11(61 \%)\end{array}$ & $\begin{array}{c}\text { No } \\
7(39 \%)\end{array}$ & \\
\hline If you knew that smoking would increase your risk of pancreatitis would you have attempted to quit earlier? & $\begin{array}{c}\text { Yes } \\
11(61 \%)\end{array}$ & $\begin{array}{c}\text { No } \\
7(39 \%)\end{array}$ & \\
\hline Are you ready to quit now? & $\begin{array}{c}\text { Yes } \\
8(44 \%)\end{array}$ & $\begin{array}{c}\text { No } \\
6(33 \%)\end{array}$ & $\begin{array}{c}\text { Unsure } \\
3(17 \%)\end{array}$ \\
\hline
\end{tabular}

other health reasons $(12 / 18)$ as the top two reasons. On this question, one patient mentioned pancreatitis as a specific reason given by her physician. Only 7 of the $18(39 \%)$ patients said that their physician indicated damage to the pancreas as a smoking risk.

The next four questions (17-21) assessed the patient's level of knowledge about the pancreas and smoking (Table 3). When asked to mark items that caused damage to the pancreas, 13 of 18 checked alcohol (72\%), (10/18; 56\%) checked smoking and $10 / 18$ checked both smoking and alcohol. When asked specifically about smoking and the pancreas, 9 said yes it did cause injury, 6 said no and 3 were unsure. The majority of the patients said that their physician was the number one source of information.

The remaining questions (22-25) were used to assess the patient's stage of change in terms of smoking cessation (Table 4). Ten out of 18 felt motivated to quit when their physician discussed smoking and its health risks. This number increased by one $(11 / 18 ; 61 \%)$ when their physician included pancreatitis as a health risk. Of those 11 , only 3 felt motivated at the time to set a quit date. Of the 6 who did not feel motivated to quit after their physician mentioned pancreatitis as a smoking risk, only 1 felt motivated to set a quit date now after learning that smoking may have increased their risk of developing chronic pancreatitis. Eleven of 18 patients (61\%) acknowledged that they would have quit earlier if they had known that smoking increased their risk of pancreatitis.

\section{Discussion}

The focus of this brief questionnaire was to assess a patients knowledge regarding the association between smoking and pancreatitis; evaluation for prior communication between a physician and patient about risk factors for pancreatic disease including smoking; and lastly to determine whether that knowledge motivated patients to take action. Although the sample size is small, one can conclude from these results that overall, physicians informed more than half the patients about the health risks involved with smoking and took it a step further by personalizing the risks to each patient. However, when specifically mentioning smoking and its effect on the development of pancreatitis, only 39\% of the patients were informed. This questionnaire shows that although the knowledge of smoking and its consequences are known, physicians are not effectively communicating with their patient's individual situations. After reviewing the information, $61 \%$ of the patients stated that they would have thought about quitting earlier if they had known that smoking exacerbated the development of pancreatitis. Another major finding of this small study was that many patients are in fact aware of the relationship between smoking and pancreatitis (10 out of 18). Patients also expressed the importance of the physician education regarding their disease.

There is very limited information on patients' understanding of smoking and its effect on the pancreas as well as physicianpatient interaction. To our knowledge, this is the first study specifically to address this latter issue. The study by Yadav et al. [7] does demonstrate that indeed physicians, even those involved with managing patients with chronic pancreatitis, have variable rates of ascribing smoking as a risk factor for chronic pancreatitis. Our small study corroborates those results. This would suggest that there indeed is a lack of recognition of this important association. Our study also suggests the potential importance of the physician-patients relationship in educating patients.

There are several important limitations of our study. The sample size is small $(n=18)$ making it difficult to generalize the findings. Nevertheless, this was a pilot study to assess use of the instrument. We also sampled patients from a specialized pancreas clinic in Alabama. We also caution that our instrument has not been validated, but rather this was a first attempt to obtain salient information regarding the patients' understanding on this association.

\section{Conclusion}

Based upon these preliminary findings, we hope to expand 
the questionnaire to be used for routine use in our patients with chronic pancreatitis to assess levels of knowledge and desire to quit smoking. Such a desire to quit should strongly prompt us to begin the process based upon local expertise. Physicians know that smoking is injurious to health, but further education regarding this association appears needed. Physicians are already limited by time, so having a basic tool that assesses the patient's level of education and stage of change for behavioral modification will be beneficial. The next step would be to setup support systems for these patients to be connected to like smoking cessation classes; easy access to medication that helps them quit smoking, and support groups.

\section{Acknowledgement}

Supported in part by grant P50 CA101955.

\section{References}

1. Braganza JM, Lee SH, McCloy RF, McMahon MJ. Chronic Pancreatitis. Lancet. 2011;377(9772):1184-1197.

2. Yadav D, Hawes RH, Brand RE, Anderson MA, Money ME, et al. Alcohol Consumption, Cigarette Smoking, and the Risk of Recurrent Acute and Chronic Pancreatitis. Arch Intern Med. 2009;169(11):1035-1045.

3. Yadav D, Slivka A, Sherman S, Hawes RH, Anderson MA, et al.
Smoking is under-recognized as a risk factor for chronic pancreatitis. Pancreatology. 2010;10(6):713-719.

4. Yadav D, Whitcomb DC. The Role of Alcohol and Smoking in Pancreatitis. Nat Rev Gastroenterol Hepatol. 2010;7(3):131-145.

5. Law R, Parsi M, Lopez R, Zuccaro G, Stevens T. Cigarette Smoking is Independently Associated with Chronic Pancreatitis. Pancreatology. 2010;10(1):54-59.

6. Maisonneuve P, Frulloni L, Müllhaupt B, Faitini K, Cavallini G et al. Impact of smoking on patients with idiopathic chronic pancreatitis. Pancreas. 2006;33(2):163-168.

7. Maisonneuve P, Lowenfels AB, Müllhaupt B, Cavallini G, Lankisch PG, et al. Cigarette Smoking accelerates progression of alcoholic chronic pancreatitis. Gut. 2005; 54(4):510-514

8. Talamini G, Bassi C, Falconi M, Sartori N, Vaona B et al. Smoking Cessation at the Clinical Onset of Chronic Pancreatitis and Risk of Pancreatic Calcifications. Pancreas. 2007;35(4):320-326.

9. Sadr-Azodi O, Andren-Sandberg A, Orsini N, Wolk A. Cigarette smoking, smoking cessation and acute pancreatitis: a prospective population-based study. Gut. 2012;61(2):262-267.

10. Nojgaard C, Becker U, Matzen P, Andersen JR, Holst C et al. Progression from acute to chronic pancreatitis: prognostic factors, mortality, and natural course. Pancreas. 2011;40(8):1195-1200. 